\title{
A FORMAÇÃO DOS PROFISSIONAIS DA SAÚDE E A PEDAGOGIA INSCRITA NO TRABALHO DO PROGRAMA DE SAÚDE DA FAMÍLIA ${ }^{1}$
}

\author{
Eliana Aparecida Villa², Antonia Vitoria Soares Aranha ${ }^{3}$
}

\footnotetext{
${ }^{1}$ Recorte da tese - Pedagogia do Cuidado: a relação de saberes e valores no trabalho do Programa Saúde da Família da Faculdade de Educação da Universidade Federal de Minas Gerais (UFMG), 2008.

2 Doutora em Educação. Professor Adjunto do Departamento de Enfermagem Aplicada da Escola de Enfermagem da UFMG. Minas Gerais, Brasil. E-mail: luavilla@gmail.com

${ }^{3}$ Doutora em Educação. Professor Adjunto da Faculdade de Educação da UFMG. Orientadora da tese. Minas Gerais, Brasil. E-mail: antoniavitoria@uol.com.br
}

\begin{abstract}
RESUMO: O objetivo desse estudo foi investigar os saberes produzidos no trabalho e as relações de saber estabelecidas no convívio entre os profissionais e usuários no Programa de Saúde da Família. Optou-se pela pesquisa qualitativa, fundamentada no referencial da ergologia. Os sujeitos foram 19 integrantes de três equipes de saúde da família. Os dados foram coletados por meio da entrevista semiestruturada e da observação de campo. A análise dos dados foi mediante uma abordagem qualitativa, fundamentada no referencial da ergologia. A análise revelou que o trabalho é um locus formador dos profissionais de saúde, no qual atuam como pioneiros da construção do Programa de Saúde da Família, num processo de construção e reconstrução de saberes, trocando experiências, num fazer complementado pelo outro. Revelou, ainda, um saber contido no corpo dos trabalhadores que se rearticula, ocorrendo uma transformação de si pela atividade, que é imprescindível para o cuidado e para a formação contínua dos profissionais.
\end{abstract}

DESCRITORES: Trabalho em equipe. Educação em saúde. Programa saúde da família.

\section{HEALTH PROFESSIONALS' FORMAL EDUCATION AND PEDAGOGY REGISTERED IN BRAZIL'S FAMILY HEALTH PROGRAM WORK}

\begin{abstract}
The objective of this paper was to investigate the knowledge produced in practice and in knowledge working relationships established among professionals and users of the Brazilian Family Health Program. Qualitative research was chosen based on the ergology referential. The subjects were 19 members of three family health teams. Data were collected through structured interviews and field observation. Data was analyzed by a qualitative approach based on the ergology referential. Analysis revealed that work is a developmental locus of the health care professionals who act as pioneers in the Brazilian amily Health Program construction, in a knowledge construction and reconstruction process, exchanging experiences and complementing each other's work. This study also revealed knowledge contained in the workers' bodies that rearticulates, with self-transformation through their activities occurring, which is indispensable for continued professional care and development.
\end{abstract}

DESCRIPTORS: Teamwork. Health education. Family health program.

\section{LA FORMACIÓN DE LOS PROFESIONALES DE LA SALUD Y LA PEDAGOGÍA INSCRITA EN EL TRABAJO DEL PROGRAMA DE SALUD FAMILIAR}

\begin{abstract}
RESUMEN: El presente estudio tiene por objetivo investigar los saberes producidos en el trabajo y conocer las relaciones que se establecen en la interacción entre profesionales y usuarios del Programa de Salud Familiar. Se optó por una investigación cualitativa, basada en los presupuestos de la ergología. Los sujetos del estudio fueron 19 integrantes de tres equipos de salud familiar. Los datos fueron recolectados por medio de entrevistas semiestructuradas y observación de campo, y se analizaron con un enfoque cualitativo, basado en los presupuestos de la ergología. El análisis reveló que el trabajo es un locus formador de los profesionales de la salud, que actúan como pioneros en la construcción del Programa de Salud Familiar, en un proceso de construcción y reconstrucción de saberes, intercambiando experiencias en un actuar que es complementado por el otro. También reveló un saber contenido en el cuerpo de los trabajadores que se rearticula, ocurriendo una transformación de sí mismos por la actividad, que es indispensable para el cuidado y para la formación de los profesionales.
\end{abstract}

DESCRIPTORES: Trabajo en equipo. Educación en salud. Programa salud de la familia. 


\section{INTRODUÇÃO}

O ensino superior médico e de enfermagem seguiu, durante muitos anos, o modelo disciplinar centrado numa racionalidade biomédica, restrito à sua dimensão biológica, com uma visão organicista do paciente e a uma análise do processo saúdedoença, enfocando prioritariamente a doença e as medidas terapêuticas aplicáveis a cada caso. $\mathrm{O}$ domínio teórico das disciplinas biomédicas, que fundamentavam a organização curricular, era a condição para o início da formação profissional.

O ensino clínico desenvolvido em sua maior parte em hospitais, permitia que de modo geral, os pacientes fossem tomados como objetos de aprendizagem, desvinculados do seu contexto, distanciados das contradições do mundo de fora, do "extra-muros". Trata-se do modelo médico hegemônico de ensino: organicista, mecanicista e ahistórico, que pode gerar uma compartimentação dos saberes, os quais permanecem isolados uns dos outros podendo ser constatada tanto na formação quanto no exercício profissional. ${ }^{1}$

Assim, pode-se depreender que a formação pautada nessas bases propicia uma prática médica na qual o profissional pode construir seu mundo próprio de experiências e assumir o tratamento dos "seus" casos, com uma autonomia profissional que está na origem da profissão e lhe garante status e controle do trabalho. Essa condição coloca o médico numa posição de dominação em relação aos demais trabalhadores da saúde. ${ }^{2}$

Em relação à enfermeira, essa formação leva a uma segmentação de diferentes conteúdos, ao descentramento do sujeito e à fragmentação do cuidado, predominando em todo atendimento o aspecto curativo. Além disso, com a divisão técnica do trabalho, a enfermeira, via de regra, é responsável pela coordenação e supervisão do serviço de enfermagem. A profissional, ao se inserir no serviço, de modo geral, passa a assumir os objetivos e processos de trabalho já determinados. Nessa perspectiva, é esperado pela instituição que a enfermeira desempenhe inúmeras tarefas além de responder pela organização, condução e supervisão do processo de trabalho, de maneira que, apesar de todo o investimento em sua qualificação, muitas vezes, ela sofre um sério desencantamento no que diz respeito ao campo de sua autonomia e de seu status profissional. ${ }^{3}$

A partir das propostas de mudanças que vêm se processando no trabalho do setor saúde, diversas reformulações no sistema de formação de seus trabalhadores vêm sendo requisitadas. Nesse sentido, os Ministérios da Saúde (MS) e da Educação têm oferecido estímulos aos processos de mudança curricular do ensino superior, que se refletem nas práticas profissionais em saúde, destacando-se as Diretrizes Curriculares Nacionais do Curso de Medicina e do Curso de Enfermagem, em 2001 pelo Conselho Nacional de Ensino. ${ }^{4}$ Tais diretrizes, buscando dar maior sustentação às transformações da área da saúde, norteiam desde os conteúdos essenciais, as propostas metodológicas, os objetivos dos cursos até o perfil dos profissionais a serem formados, visando uma capacitação comprometida com as transformações das práticas de saúde, notadamente de acordo com o contexto brasileiro de construção do Sistema Único de Saúde (SUS) e com o novo modelo assistencial.

Nessa perspectiva, o MS propôs diferentes fóruns para possibilitar o diálogo entre instituições formadoras e gestores do sistema de saúde, procurando definir os caminhos que a formação deve percorrer para atender às necessidades do SUS. Também foi oferecido apoio técnico e financeiro ao desenvolvimento das mudanças curriculares para viabilizar a adoção dessa orientação.

São muitos os desafios ainda presentes como a ampliação da clínica, a articulação entre indivíduos e coletivo no trabalho em equipes, a construção da integralidade da atenção que "[...] têm sido propostos, simultaneamente para as escolas e para o sistema de saúde. E deverão ser enfrentados conjuntamente no processo de formação e de transformação das práticas de saúde" . 5:352 Trata-se de projetos inovadores, mais críticos e criativos para que os atores vivenciem os princípios de integralidade, equidade e universalidade preconizados pelo SUS, e possam contribuir efetivamente na construção de novos modelos de atenção à saúde - que incluam o desenvolvimento do aprendizado e da prática multiprofissional como elemento estratégico da mudança.

Reconhecemos, assim, que as mudanças ocorridas no processo de trabalho, notadamente com a implantação do Programa de Saúde da Família (PSF), vêm contribuir substancialmente para a capacitação dos seus trabalhadores e a formação dos futuros profissionais que, de alguma forma, atuam nestes serviços. Ressaltamos, ainda, que as tecnologias de ação mais estratégicas capazes de efetivar a mudança estão contidas no processo de intervenção em ato, ou seja, no momento assistencial. Chamamos a atenção para esse dado, pois é no micro-espaço de trabalho, na gestão da atividade, 
que o trabalhador define as possibilidades de produção de novos comportamentos, novas posturas, novas subjetividades. ${ }^{6-7}$

Assim, o referencial ergológico nos orienta porque se pauta no movimento, na contradição e na mudança das situações de trabalho, propondo um debate constante entre as experiências de vida, onde se inclui o trabalho, e os conceitos que se modificam a partir da experiência. Para a ergologia toda atividade é sempre uma fonte de novos saberes em gestação a espera de uma conceitualização. Sob essa ótica, o espaço de trabalho pode ser entendido como sendo o lugar de encontro, o lugar de construção em comum onde se ativa uma espécie de espiral permanente de retrabalho dos saberes, que faz retrabalhar as disciplinas umas com as outras. ${ }^{7}$

Consideramos desse modo, que o trabalho diário é um locus formador do trabalhador de saúde, no qual os profissionais vêm aprendendo a lidar com as novas propostas de reformulação da assistência, como pioneiros na construção do novo modelo assistencial, num verdadeiro processo de ensino-aprendizagem no cotidiano do trabalho.

Nessa direção, verificamos que na saúde, os processos não podem ser padronizados, “[...] é impossível eliminar os imprevistos". 8:55 Ainda que haja regularidade, "[...] cada caso é um caso singular, obrigando a invenção de soluções nem sequer imaginadas". $8: 56 \mathrm{O}$ profissional exercita, o tempo todo, uma gestão de si, uma gestão que envolve escolhas, valores, arbitragens. Cada uma dessas micro-escolhas é feita partindo de valores que podem ser explícitos ou permanecer obscuros, fazendo com que cada situação de trabalho, por mais idêntica que possa parecer, seja única. Assim, o trabalhador ao gerir essas singularidades faz uso de si, buscando encontrar equilíbrio entre o prescrito, as suas próprias normas e as do coletivo, para renormalizar sua ação, modificando-a. A convocação do uso de si vai exigir uma mobilização cognitiva e afetiva do profissional, num processo constante de recriação da atividade, de aquisição e reconstrução de saberes. ${ }^{7}$

Assim, a organização das atividades que acontecem diariamente no PSF, a sua dinâmica, a comunicação entre os diversos profissionais na forma de palavra, gestos ou olhares configura, na prática, uma sincronia no trabalho, um trabalho criativo que se reconstrói a cada atividade, mas cuja criação passa despercebida pela maioria dos profissionais. Verificamos, em diferentes situações, um trabalhador aqui, outro lá, recorrendo ao auxílio do colega para uma informação ou uma opinião para a tomada de decisão. Um ritmo frenético e cotidiano que nos reporta à descrição de Cunha sobre a temporalidade ergológica nas situações de aprendizagens: "[...] O tempo da tarefa prescrita esquadrinha os gestos individuais e coletivos e demanda ajustamentos permanentes entre tempos profissionais e privados. No fluir do tempo esquadrinhado da tarefa, muitas equipes de trabalho constroem, através da sincronia e coordenação de seus gestos, códigos e regras do viver junto, formas de partilhar aprendizagens e valores em comum no trabalho, de transmitir saberes. Sem esse tempo carregado de aprendizagens em comum, de partilhas, de frequentação mútua no esquadrinhamento do tempo a ser compartilhado, não pode haver trabalho cooperativo". $9: 13$

O estudo do trabalho implica, então, no conhecimento dos saberes e valores envolvidos na atividade e, ao mesmo tempo, no reconhecimento da carga significativa destes sem generalizá-los, pois as decisões são sempre históricas e circunscritas a uma situação local.

Assim, o objetivo desse estudo foi investigar os saberes produzidos no trabalho e as relações de saberes e valores estabelecidas no convívio entre os profissionais e usuários no PSF.

\section{METODOLOGIA}

Dentre os percursos das investigações qualitativas, fizemos a opção pelo Estudo de Caso, tomando um Centro de Saúde como uma unidade representativa da Rede Básica de Saúde de Belo Horizonte. ${ }^{10} \mathrm{~A}$ coleta de dados ocorreu após aprovação do Comitê de Ética em Pesquisa (CEP) da Universidade Federal de Minas Gerais (UFMG), utilizando como instrumentos a análise documental, entrevistas semiestruturadas e a observação de tipo etnográfica. Participaram como sujeitos do estudo os membros das três equipes de saúde da família: três Médicas (M), seis Auxiliares de Enfermagem (AE), três Enfermeiras (E), seis Agentes Comunitários de Saúde (ACS) e a Gerente $(G)$. Todos os sujeitos concordaram em participar do estudo, tendo sido informados sobre os aspectos metodológicos e ético-legais. Desse modo, para se manter o anonimato, eles foram identificados com a(s) letra(s) da categoria profissional, e numerados conforme a ordem da entrevista. A pesquisa foi conduzida de acordo com os padrões éticos exigidos na Resolução $\mathrm{N}^{\circ}$ 196/96 do Conselho Nacional de Saúde, aprovada pelo CEP/UFMG, Parecer N ${ }^{\circ}$ ETIC 20/ 05 e Protocolo CAAE- 0420.0.203.000-05. 
A coleta de dados ocorreu no período de março a julho de 2007. Todos os integrantes das três equipes de saúde da família eram mulheres e, por essa razão, a referência aos sujeitos do estudo será feita no feminino. Foram realizadas 19 entrevistas, gravadas e transcritas pela pesquisadora. Utilizamos o diário de campo para anotação dos fatos e ocorrências durante as observações. Foram elaborados 27 diários, a maioria deles com observações realizadas nos dois períodos de funcionamento da unidade, manhã e tarde.

A condução do processo analítico dos dados obtidos seguiu as sugestões de interpretação qualitativa por meio da codificação inicial dos registros e posterior análise dos conteúdos com a criação de categorias fundamentadas no referencial teórico da ergologia e do trabalho em saúde. ${ }^{10}$

\section{RESULTADOS E DISCUSSÃO}

Desde as primeiras entrevistas e observações realizadas, foi possível constatar que o cotidiano do trabalho em saúde constitui-se numa relação intensa de troca de saberes e cooperação entre as profissionais, sem a qual o serviço não se desenvolveria. Destacamos o modelo instituído no PSF pelo modo de organização do trabalho em equipe, que aproxima os envolvidos, colocando-os numa relação de interdependência. A co-responsabilização por uma população adscrita propicia uma atenção compartilhada, com estabelecimento de objetivos comuns e criação de vínculo entre profissionais e usuários.

No atendimento diário, cada trabalhador contribui com suas competências específicas, com recortes diferenciados do problema trazido, que vão conformar diferentes maneiras de cuidar, permitindo a troca de saberes, num fazer complementado pelo outro. Nesse sentido, os profissionais constroem e reconstroem os seus saberes e rearticulam o processo de trabalho, ao mesmo tempo em que reafirmam o que já está estabelecido, de acordo com as suas possibilidades e aquelas oferecidas pelo meio. $^{2}$

No estudo, foi possível registrar diversos depoimentos mostrando que diferentes profissionais trocam saberes nas mais variadas situações.

[...] Assim, cada um tem uma visão, essas visões se completam, mas ninguém substitui ninguém [...] Eu uso muito os saberes dos demais quando tenho dúvidas, e aprendo muito com isso (M3).

Ou como aponta outro depoimento: [...] Com o PSF melhorou muito a relação. Muito, porque a gente vai discutindo com os colegas, vão passando pra gente [...] A gente troca muito e a gente sempre aprende algo novo (E1).

Essa troca permite a ampliação dos saberes: [...] você acrescenta o conhecimento que ele [ACS] tem da comunidade. Ele me traz a vivência dele lá, de como vive a família - ao que a gente não tem acesso e ele tem; seus costumes, sua situação financeira (E3).

A implantação do PSF determinou uma nova organização do trabalho e um novo perfil de usuários passou a ser atendido na unidade básica, gerando um aumento na demanda pelos serviços. Verificamos, todavia, que para os médicos, essa mudança de perfil foi crucial, uma vez que muitos deles desempenhavam a função como especialistas e passaram a atender como generalistas, exigindo assim, uma reconstrução dos saberes até então utilizados no cotidiano assistencial.

Uma das participantes do estudo era ginecologista, a outra atendia a clínica de adultos, ambas passaram a atender crianças, homens, mulheres, adolescentes e idosos, em cada uma das suas peculiaridades relativas ao processo saúde-doença. As profissionais revelam que foram muitas as dificuldades enfrentadas, mas aos poucos foram se capacitando por meio da atividade de trabalho: [...] Como ginecologista não via pediatria desde que me formei! E tive que atender pediatria. Então tinha que discutir com a pediatra [...] foi uma troca de saber muito positiva. Fomos aprendendo juntos [...] (M1).

Embora cada profissional mantenha a identidade dos núcleos de conhecimento formalizado, a relação de saberes no trabalho ultrapassa esses limites, permitindo que as trabalhadoras busquem junto aos demais membros da equipe, o apoio necessário para a complementação de sua competência teórica ou prática: [...] Antes eu era ginecologista [...] E tratar de criança não foi fácil, porque muitas vezes você não ausculta o peito chiando. É preciso um treino de ouvido e de visão que elas [enfermeiras] tinham e eu não tinha. Fui adquirindo junto com elas, e elas me ajudando (M1).

Constatamos, pelo depoimento acima, que a atividade industriosa não tem como se sustentar somente no aporte teórico, num protocolo a ser seguido, mas é imprescindível o desenvolvimento da habilidade prática adquirida com a experiência do trabalho. Encontramos aqui os ingredientes da competência, apontados por Schwartz: o primeiro ingrediente envolve a capacidade humana de criar conceitos, de conceber formas de intervenção, de aprender como. ${ }^{11} \mathrm{Na}$ área da saúde podemos relacioná-los com a formação teórica dos profissio- 
nais e às formas de intervenção apropriadas, tendo como exemplo, os protocolos contidos nos manuais, que norteiam as diferentes formas de ação.

Já o segundo ingrediente seria relativo aos processos de renormalizações, isto é, à dimensão da experiência ou da singularidade. Trata-se dos saberes que resultam da vivência concreta da atividade de trabalho em diferentes situações, nas particularidades que exigem do profissional o uso de si, no que elas têm de mais singular. ${ }^{11}$

Assim, os médicos, ao serem confrontados com um novo perfil de usuário, foram, aos poucos, reconstruindo os saberes a partir de novas sínteses do campo sensorial, físico, cognitivo e psíquico, no desenvolvimento de habilidades para o novo atendimento: [...] o exame físico da criança pra mim foi muito difícil, tinha muito tempo que não atendia criança $e$, na prática as coisas são totalmente diferentes [...]. Como a palpação, eu sabia tudo pro adulto: tudo graaaande, o fígado graaande, [risos] mas e o bebê? No começo me senti muito insegura, até a ausculta da criançaédiferente, você primeiro tem que acostumar o ouvido (M3).

No depoimento acima fica explícito que, para atender aos desafios do novo modelo e dar conta da atividade real, a médica rearticula suas capacidades para o exame físico da criança, cuja memória fora conformada na atividade assistencial com adultos. É o mesmo corpo que enfrenta, se experimenta, se forma, se usa em todas as situações da vida. ${ }^{12}$

Também as enfermeiras citam a necessidade do recentramento do corpo para o desempenho do cuidado: [...] Eu tinha que fazer coleta de material cérvico-uterino que eu só tinha visto na teoria [...] e aí na prática você vai vendo que uma tem um colo mais apertadinho, uma o canal vaginal é mais longo, a forma de colocar o espéculo, o jeito e aquela viradinha pra facilitar. Isso aprendi fazendo e não está em livro nenhum, isso é só a prática (E3).

A atividade não tem como ser padronizada, cada novo usuário que chega confirma a incerteza da situação, o que nos remete ao terceiro ingrediente da competência, que se refere à capacidade do profissional instaurar uma dialética ou uma consonância entre os dois primeiros ingredientes. ${ }^{11}$ Trata-se de saber como articular conceitos e técnicas aprendidos com as situações singulares que solicitam adaptações e transformações desses instrumentos.

[...] No começo as veias mais difíceis sempre sobravam pra mim, é que a gente já tem o jeito, sabe das manhas [risos] e aí eu chamava a auxiliar e a gente ia fazendo junto [...] (E1).
A troca de conhecimentos permite a ampliação das competências das trabalhadoras, que de forma muito sutil, vão adquirindo cada vez mais segurança e autonomia para o desenvolvimento das atividades, sem que com isso se esgote a possibilidade de surgimento do novo, pois o trabalho em saúde se faz no espaço da imprevisibilidade. ${ }^{11}$

O PSF trabalha diferentes potencialidades para a mudança de modelo, priorizando o vínculo com a população, propicia um rompimento no comportamento passivo dos profissionais dentro das unidades de saúde permitindo a extensão das ações para e na comunidade. Visa aumentar as possibilidades de se lidar diretamente com a demanda trazida pelo usuário e sua realidade de vida, buscando juntos, soluções para as questões levantadas. ${ }^{13}$ Nesse encontro, a troca ocorre quase que naturalmente: [...] A troca de experiência é muito grande mesmo, vou aprendendo com a simplicidade deles, como lidam com as dificuldades na vida. Aprendo a simplicidade da linguagem, como expressam seus males; aprendo nas soluções simples que eles arrumam - $e$ aí eu até uso o exemplo de um, com outros pacientes [...] (M2). O conhecimento da realidade enfrentada pelos usuários e as formas de que se utilizam para lidar com a vida são saberes determinantes para a conduta dos profissionais.

As profissionais, portanto, explicitam em seus relatos o desenvolvimento de uma ação interativa absorvida numa troca de conhecimento junto aos usuários, aprendendo com eles, seus hábitos e costumes: [...] A gente aprende como as pessoas se cuidam, suas estratégias de vida e se vê obrigado a ampliar o saber científico, pois ele vai dar sustentação àquilo que nos pega de surpresa [...] (M3).

Cada profissional domina um leque de conhecimentos que será utilizado de acordo com a situação, de modo que, no cotidiano do serviço, há uma articulação entre as diferentes trabalhadoras, buscando juntas, as soluções possíveis para responder efetivamente aos problemas que chegam. Nesse sentido, comumente, as relações de saberes são facilitadas pelo intercâmbio de informações realizado nas reuniões da equipe: [...] O trabalho no PSF facilitou muito a troca de saberes, porque essa coisa de sentar junto, se reunir, discutir um caso, discutir uma dificuldade sempre aumenta o conhecimento (E3).

As reuniões das equipes de saúde da família têm por objetivo, por um lado, acompanhar os casos atendidos e nortear a atuação dos profissionais e por outro lado, capacitar os seus mem- 
bros. ${ }^{14}$ Contudo, por vezes, estas acontecem de forma rápida, há uma pauta a ser seguida para o controle das atividades propostas e os casos são comentados brevemente, sem que a médica ou a enfermeira tomem consciência das necessidades dos demais. Tal fato diminui as possibilidades de participação ativa do grupo, comprometendo um dos propósitos do trabalho em equipe que é a educação continuada dos seus integrantes. ${ }^{15}$

Diante da descrição acima, lembramos da valoração desigual atribuída às diferentes categorias profissionais que dificulta tanto a concretização da interdisciplinaridade dos saberes, quanto a interatividade entre trabalhadores. Nessa direção reafirmamos a necessidade de que os profissionais assumam uma atitude de "desconforto intelectual" 2:148 diante de seus próprios saberes, questionem a sua formação e estejam abertos à contribuição dos demais de modo a "repensar o seu jeito de agir". 2:148

Pelos depoimentos coletados, pode-se perceber que, aos poucos, as profissionais vão reconhecendo a importância do seu conhecimento no desenvolvimento do trabalho diário, contribuindo, cada vez mais, para a resolução de problemas de forma compartilhada. Nesse sentido, não podemos deixar de salientar que, em diversos depoimentos, as ACSs e as AEs reportaram-se aos saberes adquiridos no processo de ensino-aprendizagem com a enfermeira: [...] A enfermeira que me deu confiança pra sair pras visitas. Quando cheguei não sabia nada, pensei que não ia dar conta [...] Aprendi tudo aqui com a enfermeira [...] (ACS2).

O trabalho das ACSs, logo que foram admitidas nas unidades de saúde, foi todo orientado pelas enfermeiras sem nenhum outro tipo de capacitação subseqüente, uma vez que a qualificação destes só foi definida pelo MS nos últimos anos: [...] com o PACS teve a capacitação do ACS pro cadastramento das famílias, e todo processo de capacitação nós assumimos aqui no trabalho [...], foi como trocar a roda do carro com ele andando [...] (E2).

Quanto às AEs, a maioria delas ao chegar ao serviço, boa parte recém-formada, demandou um trabalho educativo gradual, adquirindo e mobilizando os saberes da e na atividade - num aprender-fazendo: [...] No começo ela fazia, eu olhava [...], eu chegava e falava: - Olha, vou fazer isso e isso e ela dizia é isso aí, vai firme! Cada vez fui adquirindo mais confiança e firmeza (AE5).

A maneira como a relação entre o saber e o fazer é retratada, mostra que um implica e é implicado pelo outro, teoria e prática não existe isoladas, um não existe sem o outro, mas se encon- tram em uma unidade indissolúvel que envolve o sujeito com quem se interage. Parafraseando Freire, podemos dizer que a aquisição de saberes no trabalho em saúde: "Não pode se fazer de cima para baixo, nem de fora para dentro, como uma doação ou uma exposição, mas de dentro para fora pelo próprio sujeito, somente ajustado pela enfermeira" . 16:72

A enfermeira flexibiliza, assim, a rotina de trabalho instituída, propondo formas de fazer a partir dos casos concretos, presentes e emergentes. Ela cria oportunidades de aprendizado, atentando para o interesse, as necessidades e as possibilidades dos demais integrantes da equipe de saúde da família. Verificamos, pelos discursos, que a dinâmica pedagógica utilizada permitiu uma aprendizagem gradual, promovendo um avanço para níveis mais complexos de acordo com as capacidades e ritmo de cada um.

A ação pedagógica presente no cotidiano de trabalho da equipe de enfermagem é responsável pela troca dos conhecimentos necessários para que as trabalhadoras dominem sua atividade de trabalho. Vale ressaltar que o saber que temos da atividade é somente uma representação desta; fazemos uma idéia do que será realizado, porque o essencial na mobilização de saberes está no ato em si, no cuidado executado pelas trabalhadoras. ${ }^{11}$

O depoimento de uma enfermeira deixa claro que, diante das imprevisibilidades da atividade, é necessário buscar soluções no coletivo de trabalho para que o seu desempenho possa ser qualificado e qualificante: [No PSF] você lida com vários problemas, não é somente a saúde. Você lida com a questão ética em casos que, sem dúvida, mexem com a gente; [...] por isso é, também um aprendizado pra vida e sei que eu não vou resolver tudo isso sozinha! (E3).

Na medida em que a profissional busca soluções compartilhadas e implicadas com o trabalho interdisciplinar, essa organização aponta para um equilíbrio das competências, ativada pelo potencial ampliado da atividade, no qual sinergias bem sucedidas supõem, em parte, a competência individual e em parte as competências coletivas, modificando assim, a gestão da atividade. ${ }^{11}$

A proposta de projetos terapêuticos interdisciplinares reduz, cada vez mais, a tendência dos profissionais em manterem-se em seus núcleos restritos de conhecimento, segundo a sua formação original, ampliando, desse modo, o leque de saberes de cada um e do grupo. ${ }^{13}$ Constatamos, assim, a dimensão da clínica ampliada, assistência que comporta o encontro entre necessidades e proces- 
sos de intervenção tecnologicamente orientados, visando um acompanhamento interdisciplinar dos casos, onde termo ampliada assume distintas significações relativas a uma atenção ampla ao usuário, bem como às relações ampliadas entre as profissionais envolvidas. ${ }^{18}$

\section{CONSIDERAÇÕES FINAIS}

Este estudo, portanto, tem a intenção de contribuir para a discussão do trabalho em saúde como um locus formador do ser humano, na medida em que aponta diferentes possibilidades de reconstrução e aquisição de saberes no cotidiano de trabalho dos integrantes das equipes de saúde da família.

Todo trabalhador, traz em si, um conjunto de saberes e valores que são manifestados nas relações consigo mesmo, com o mundo e com o outro. O trabalho em saúde é definido no encontro entre quem produz e quem recebe, ocorrendo assim, uma transformação do trabalhador e do outro pela atividade, que é imprescindível para a eficiência do cuidado.

Os profissionais desenvolvem as habilidades físicas, num exigente uso de si, um reajustamento indefinido que leva em conta a sua corporeidade, bem como o real do corpo do usuário. São saberes da experiência que dificilmente podem ser explicitados, mas que se configuram no desenvolvimento da atividade e são, por meio dela, legitimados.

Finalizando, pudemos observar em vários relatos, bem como nas observações realizadas, que o trabalho no PSF vem se constituindo numa perspectiva interdisciplinar, na qual os profissionais buscam soluções conjuntas e novas práticas que incluam a participação do usuário. Dessa forma, as alterações nas relações de trabalho tornam-se mais fundamentadas e comprometidas com conceitos e valores radicalmente diferentes daqueles dominantes no modelo médico tradicional. Os profissionais passam a discutir condutas, compartilhar decisões, preocupados com os sujeitos e os meios mais apropriados para a sua implicação no cuidado à saúde.

Constatamos, assim, que a capacidade de gerir as situações que se apresentam para o trabalho em equipe solicita dos trabalhadores novas aprendizagens a partir da vivência, reinventando relações numa gestão mais democrática da atividade, sendo necessário para isso, maior distribuição de poder e confiança nas capacidades e saberes do outro.

\section{REFERÊNCIAS}

1. Falcón GS, Erdmann AL, Meirelles BHS. A complexidade na educação dos profissionais para o cuidado em saúde. Texto Contexto Enferm. 2006 Abr-Jun; 15(2): 343-51.

2. Scherer MDA. O trabalho da equipe no programa de saúde da família: possibilidades de construção da interdisciplinaridade [tese]. Florianópolis (SC): Universidade Federal de Santa Catarina. Programa de Pós-Graduação em Enfermagem; 2006.

3. Villa EA. Educação em saúde: a prática educativa no cotidiano do trabalho do profissional. In: Gazzinelli MF. Reis DC; Marques RC. Educação em saúde: teoria, métodos e imaginação. Belo Horizonte (MG): Editora UFMG; 2006. p.43-51.

4. Conselho Nacional de Educação/Câmara de Educação Superior (BR) Resolução $N^{\circ}$ 3, de 7 de novembro de 2001: institui as Diretrizes Curriculares Nacionais do Curso de Graduação em Enfermagem e Medicina. Brasília (DF): Conselho Nacional de Educação; 2001.

5. Feuerwerker L, Almeida M. Diretrizes Curriculares e Projetos Pedagógicos: é tempo de ação!. Rev Bras Enf. 2003 Jul-Ago; 56 (4):351-2.

6. Merhy EE. Saúde, Cartografia do trabalho vivo. São Paulo (SP): Hucitec; 2002.

7. Schwartz Y. Trabalho e uso de si. Pro-posições. 2000 Jul; 1(5):34-50.

8. Campos GWS. Um método para análise e co-gestão de coletivos. São Paulo (SP): Hucitec; 2000.

9. Cunha DM. Notas conceituais sobre atividade e corposi na abordagem ergológica do trabalho. In: Anais da 30 Reunião Anual da Associação Nacional de PósGraduação e Pesquisa em Educação. 2007 Out 08-11, Caxambu. Rio de Janeiro (RJ): ANPED; 2007 [acesso 2007 Nov 20]. Disponível em: http://www.anped. org.br/reunioes/30ra/trabalhos/GT09-3586--Int.pdf

10. Ludke M, André MEDA. Pesquisa em educação: abordagens qualitativas. $9^{a}$ ed. São Paulo (SP): EPU; 2005.

11. Schwartz, Y. Os ingredientes da competência: um exercício necessário para uma questão insolúvel. Educ Soci [online]. 1998 Dez [acesso 2005 Ago 30]; 19 (65):101-40. Disponível em: http:/ / www.scielo.br/scielo.php?script=sci_ arttext\&pid=S0101-733019980 00400004

12. Schwartz Y. Trabalho e valor: tempo social. Rev Sociol USP. 1996 Out; 8(2):147-58.

13. Campos, G. W. S. Equipes de referência e apoio especializado matricial: um ensaio sobre a reorganização do trabalho em saúde. Ciênc Saúde Coletiva [online]. 1999 Nov [acesso 2007 Nov 22]; 4(2):393-403. Disponível em: http:/ / www.scielo. br/pdf/csc/v4n2/7121.pdf

14. Ministério da Saúde. (BR). Guia prático do Programa Saúde da Família, Brasília (DF): O Ministério; 2001. 
15. Peduzzi M. Equipe multiprofissional de saúde: conceito e tipologia. Rev Saúde Pública. 2001 Fev; 35(1):103-9.

16. Freire P. Educação e mudança. $31^{\mathrm{a}} \mathrm{ed}$. Rio de Janeiro (RJ): Paz e Terra, 2008.

17. Franco TB, Merhy EE. Programa de Saúde da família: contradições de um programa destinado à mudança técnico-assistencial. In: Merhy EE, Miranda Jr H, Rimoli J, Franco TB, Bueno WS. O trabalho em saúde: olhando e experienciando o SUS no cotidiano. $2^{\mathrm{a}} \mathrm{ed}$. São Paulo (SP): Hucitec; 2004. p.55-124.

18. Campos GWS. Saúde Paidéia. São Paulo (SP): Hucitec; 2003. 